\title{
Materials science research for sodium cooled fast reactors
}

\author{
BALDEV RAJ \\ Indira Gandhi Centre for Atomic Research, Kalpakkam 603 102, India
}

\begin{abstract}
The paper gives an insight into basic as well as applied research being carried out at the Indira Gandhi Centre for Atomic Research for the development of advanced materials for sodium cooled fast reactors towards extending the life of reactors to nearly 100 years and the burnup of fuel to $2,00,000 \mathrm{MWd} / \mathrm{t}$ with an objective of providing fast reactor electricity at an affordable and competitive price.
\end{abstract}

Keywords. Nuclear energy; fast breeder reactors; materials science; stainless steels; sodium.

\section{Introduction}

The fast growing energy demand and concerns about climate changes require nuclear energy to play a role among other energy sources to satisfy future energy needs of India. Of the available technology options, water reactors and fast breeder reactors (FBRs) with closed fuel cycle, i.e. with recovery of fuel material from the irradiated fuel by recycle, are proving to be inevitable technology options to provide sustainable energy security for India. India has matured in several advanced fields of fast breeder and associated nuclear fuel cycle technologies. Materials science, engineering and technologies have a deterministic influence on the advancement and success of fast breeder programme.

Materials in sodium cooled fast spectrum reactors and reprocessing plants are exposed to challenging environments of radiation, temperature, stress and chemicals necessitating development of advanced fuel, structural and functional materials. The science and technology efforts required to realize fuel, structural materials and components of FBRs and associated reprocessing plants need careful nurturing of a wide spectrum of knowledge base, expensive and rare facilities such as research reactors, hot laboratories and corrosion loop, expertise in a wide domain of interwoven interdisciplinary fields encompassing chemistry and physics of materials, computer simulation and modeling, manufacturing, repair and in-service inspection.

This paper gives an insight into the basic as well as applied research being carried out for the development of advanced materials for sodium cooled fast reactors. First we give a brief description on nuclear fission and breeding and then highlight the merits of having fast breeder reactors with closed fuel cycle which is followed by a brief summary of FBR programme in India. The next section highlights the challenges in developing science and

(dir@igcar.gov.in) technology which is followed by our achievements in materials science research in fuel, core structural materials. As far as coolant is concerned, the liquid metal, particularly sodium, has been the preferred choice. The next section deals with our achievements in the domains of sodium chemistry, sensors, non-destructive evaluation and nuclear waste management.

\section{Nuclear energy}

\subsection{Concept of nuclear fission and breeding}

Fission is a nuclear reaction where a fissile atom, after absorbing a neutron splits into mainly two atoms of nearly equal masses (fission products). Fission, apart from generating fission products, generates more than one neutron and also releases large amount of energy. Such reactions are possible in heavy atoms such as Uranium-235, Plutonium-239 and Uranium-233, which are called fissile isotopes. Natural uranium contains about $0.7 \%$ Uranium-235 and the rest is Uranium-238. Other two i.e. Plutonium239 and Uranium-233, are not naturally occurring isotopes. They are generated by a process called nuclear radioactive transmutation (capture of one neutron followed by two successive emissions of beta particles) of Uranium238 and Thorium-232 (simply thorium), respectively. These two are called fertile isotopes. Natural uranium and thorium are the naturally occurring nuclear fuel materials. The energy generated by fission in one fissile nucleus is $\sim 3 \times 10^{-18} \mathrm{kWh}$. Since $1 \mathrm{~kg}$ of Uranium 235 contains about $2.5 \times 10^{24}$ nuclei, $1 \mathrm{~kg}$ of natural uranium containing about $7 \mathrm{~g}$ of Uranium 235 has an electricity potential of $\sim 52,500 \mathrm{kWh}$. The number of neutrons generated from fission per neutron absorbed in the fissile material, called ' $\eta$ ' depends upon the energy of neutron when it gets absorbed. For fission reaction to be sustainable, $\eta$ should be greater than 1 . Table 1 gives the ' $\eta$ ' value.

It emerges from the above statistical numbers that fast reactor with natural uranium is not possible since $\eta$ is less 
Table 1. ' $\eta$ ' values for various nuclear fissile isotopes.

\begin{tabular}{lcccc}
\hline Reactor types & Natural uranium & Uranium 235 & Uranium 233 & Plutonium 239 \\
\hline Thermal & $1 \cdot 34$ & $2 \cdot 04$ & $2 \cdot 26$ & $2 \cdot 06$ \\
Fast & $<1$ & $2 \cdot 20$ & $2 \cdot 35$ & 2.75 \\
\hline
\end{tabular}

than unity. Fast reactors yield higher number of neutrons, the highest yield being with Plutonium-239. In order to maintain the steady state energy generation, one neutron must be reserved to continue the fission chain in addition to neutrons that would be lost unproductively (due to capture and leakage). The excess of neutrons thus generated is the key parameter in the nuclear fission scenario, which is the measure of quality of the fissile element with respect to breeding, a concept of artificial (man-made) production of fuel for nuclear reactors. The breeding ratio (breeding ratio $(\mathrm{BR})=$ fissile mass produced/fissile mass destroyed) needs to be higher than 1.03 for significant utilization of U-238 in any reactor system. A reactor system in which this has been realized is called a 'fast breeder reactor'. This category of reactors can sustain energy production without any external feed of fissile material; but accumulate extra fissile material in the reactor, which can be used for feeding a new reactor after reprocessing. In advanced FBRs, it is possible to achieve a breeding ratio of up to 1.5 .

\subsection{Importance of FBR with closed fuel cycle}

With the limited nuclear resources available in the country and considering the recent substantial increase in uranium prices, FBR with closed fuel cycle, in view of its efficient use of uranium, is an inevitable option. Further FBRs are essential for converting thorium to ${ }^{233} \mathrm{U}$, required for third stage of Indian nuclear power programme. FBR is a very efficient system for handling actinides and long lived fission products in the domain of waste management. FBR can be designed to incinerate high level wastes arising from the reprocessing of spent fuel. In the concept of integrated FBR with co-located fuel cycle, it is possible to derive wealth from waste, i.e. fission products, such as

${ }^{137} \mathrm{Cs}$, will be separated and used as a radiation source for various societal applications. This approach minimizes the quantity of waste to be immobilized. Separation of noble metals such as palladium for societal applications such as catalysts, fuel cells etc is also possible.

\section{FBR Programme in India}

The seed for fast reactor programme in India was sown through the establishment of a research centre (then called Reactor Research Centre) in 1972 dedicated to the development of fast reactor technology and the decision to construct fast breeder test reactor (FBTR) at Kalpakkam. FBTR is a sodium cooled loop type $40 \mathrm{MWt} /$ 13.2 MWe experimental reactor commissioned in 1985 with a unique plutonium rich carbide fuel $(70 \% \mathrm{Pu}$ and $30 \% \mathrm{U})$. The experience gained in the construction, commissioning and operation of FBTR as well as 390 reactor-years worldwide FBR operational experience, rich experience with MOX fuel, 30 years of focused R\&D programme involving extensive testing and validation, material and manufacturing technology development and demonstration, peer reviews and synergism among DAE, R\&D Institutions and Industries, have provided the necessary confidence to launch a Prototype FBR of $500 \mathrm{MWe}$ capacity (PFBR). The reactor construction was started in 2003 and the reactor is scheduled to be commissioned by 2010. As a follow-up to PFBR, it is planned to construct a couple of twin units of 500 MWe reactors, with improved economy and safety during 2010-20. Various elements of reactor design are being carefully analysed with the aim of introducing innovative features towards further reduction in unit energy cost and enhancing safety in these reactors. Clear strategies have been identified to simplify the design, reduce construction time, enhance the burnup and close the fuel cycle with minimum cooling and outof-pile inventory, without sacrificing overall safety during entire process. It is targeted to bring down the unit energy cost by $\sim 25 \%$. Further, with advanced structural materials for clad and wrapper, a burnup of $25 \mathrm{at} \%$ is envisaged for mixed oxide fuels.

It has been realized that for enhanced growth of fast reactors in the country, it is imperative to develop metallic fuelled FBRs, which promise highest breeding. A comprehensive programme on development of metal fuelled reactor and its fuel cycle has been undertaken with the aim of introducing metal fuel in commercial FBRs by 2020. Fabrication of test metal fuel pins for irradiation in FBTR and pilot plant for pyrochemical reprocessing of the spent metal fuel are the firm action plans under implementation. Directed research to develop metallic fuels for achieving high breeding ratio (1.45) and high burn up of $\sim 25$ at $\%$ is the target; based on which a spectrum of activities with synergism have been undertaken in the Department of Atomic Energy.

In the following paragraphs, challenges and achievements in the science and technology of FBR and fuel cycle, highlights of R\&D, future plans and roadmap for achieving robust growth of fast breeder reactor technology with closed fuel cycle in India, are highlighted. In this paper, 
the term FBR refers to the sodium cooled fast breeder reactors.

\subsection{Challenges in FBR science and technology}

Developing suitable structural materials is the most important key issue as the governing factor for the end of life for the fast reactor fuels is structural material, not the fuel. This calls for extensive R\&D in both science and technology including post irradiation examination (PIE) techniques to achieve a target burnup of $200 \mathrm{kWd} / \mathrm{g}$. As far as coolant is concerned, the liquid metal, particularly sodium has been the preferred choice. However, there are many challenging issues in both science and technology, that have been resolved and there are a few issues yet to be addressed, particularly in the domains of sodium chemistry, sensors, mechanical behaviour of materials in sodium, non-destructive evaluation (NDE), especially in-service inspection (ISI) techniques in sodium, thermal hydraulics and structural mechanics. These apart, to meet the requirements of commercial deployment and sustainability, FBR and closed fuel cycle have to be designed with improved economy and enhanced safety. Among the many parameters which decide this, higher temperatures with long design life is the key issue which calls for extensive $R \& D$ in the domain of materials and mechanics. High neutron flux in FBR causes material damage due to irradiation, compared to thermal neutron reactors. Sodium, because of its opaqueness poses problems for ISI. Sodium leak is also of concern for the operation and maintenance of FBRs. However, low operating pressure in FBR offers advantage over thermal reactors in terms of structural integrity. Higher operating temperatures in FBR yield higher thermodynamic efficiency which coupled with higher burn up lead to economic advantage.

\subsection{Development of fuel materials}

Solid solutions of the oxides, carbides or nitrides of uranium and plutonium or their alloys are the candidate fast reactor fuels. In the $40 \mathrm{MWth}$ FBTR, uranium-plutonium mixed carbides containing 70\% (Mark-I) and 55\% plutonium carbide (Mark-II) along with 5-20\% sesqui-carbides have been used as the fuel. FBTR has successfully operated since 1985 and the Mark-I fuel has been irradiated to a burn-up of $160 \mathrm{GWd} / \mathrm{t}$ without any fuel pin failure. Many challenges were overcome in the development of carbide fuel cycle. Carbide fuels are prepared by carbothermic reduction of the $(\mathrm{U}, \mathrm{Pu})$ oxides in the temperature range of $1700-1900 \mathrm{~K}$. The fuel material prepared by carbothermic reduction contains significant amounts of oxygen. The optimum temperature of reduction was chosen based on the equilibrium $\mathrm{CO}$ and $\mathrm{Pu}$ pressures over the $\mathrm{MC}_{1-x} \mathrm{O}_{x}+\mathrm{MC}_{1.5}$ two-phase field where $\mathrm{M}=(\mathrm{U}, \mathrm{Pu})$. Modelling activities on these fuel systems enabled com- putation of the equilibrium pressures (Saibaba et al 1987; Anthonysamy et al 1989). Figure 1 shows that efforts to reduce the oxygen contents below the cross over point between the curves for $\mathrm{Pu}(\mathrm{g})$ and $\mathrm{CO}(\mathrm{g})$ pressures at a given temperature would result in loss of $\mathrm{Pu}$ by vapourization. Based on these results, the optimum temperature of reduction was decided to be $1900 \mathrm{~K}$ so as to minimize $\mathrm{Pu}$ losses as well as reduce the oxygen content. The carbon to metal ratio of the carbide fuel is another key parameter which tends to decrease with burn-up as well as from centre to periphery of the fuel during irradiation. It results in the formation of more noble metals at the fuelclad interface and bonding of the fuel and cladding causing fuel-clad mechanical interaction. The specifications of the sesquicarbide, oxygen and nitrogen contents of the carbide fuel as well as the flow sheet were optimized based on systematic studies. Key thermophysical properties of these fuel materials such as thermal conductivity and melting temperature (Sen Gupta et al 1986) that decide the linear heat rating were measured. The fuel pin design was based on these data. The melting temperature was determined by the incipient melting technique (Sen Gupta et al 1986) and the thermal diffusivity by laser flash technique (Sen Gupta et al 2003). A specially designed out-of-pile set up was used for simulating the thermal behaviour of the fuel to determine the maximum linear heat rating (Antony et al 1997) to which the fuel can be subjected to. Methane-hydrogen gas equilibration and isopiestic are the two techniques used for the measurement of the important thermochemical property, viz. carbon potential. The measured carbon potentials of Mark-I and Mark-II fuel compositions and that of the clad indicated that carburization of the clad will not occur.

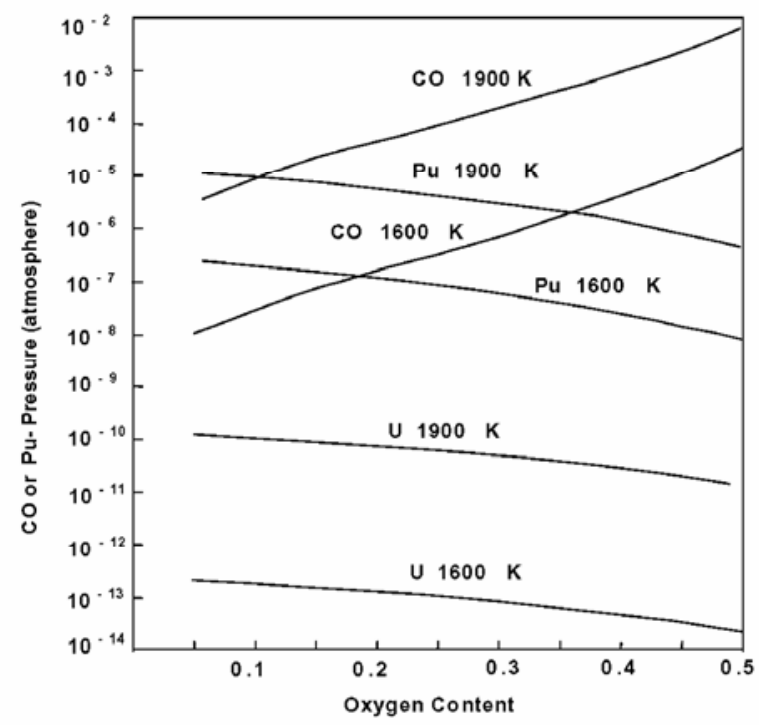

Figure 1. Equilibrium pressures over the 2-phase field $\mathrm{MC}_{1-x} \mathrm{O}_{x}+\mathrm{MC}_{1.5}$ for $\mathrm{Pu} /(\mathrm{U}+\mathrm{Pu})=0 \cdot 70$. 
Low values of carbon monoxide pressures obtained by measurement ruled out any possibility of gas phase carburization. The compatibility between the fuel with the sodium coolant as well as with the stainless steel clad was established using capsule experiments (Ganguly and Sengupta 1988).

The 500 MWe PFBR will use uranium-plutonium mixed oxides containing 21 and $28 \% \mathrm{PuO}_{2}$ as the fuels for the inner and outer cores. The fuel will be in the form of annular pellets. A 37 pin fuel sub-assembly containing mixed oxide fuels with $29 \% \mathrm{PuO}_{2}$ is undergoing test irradiation in FBTR and has attained a burn-up of $84 \mathrm{Gwd} / \mathrm{t}$ burnup. Thermophysical properties of the oxide fuels have been experimentally measured (Kandan et al 2004).

It is proposed to introduce metallic fuels in the FBRs after 2020 to ensure rapid growth of nuclear energy. Quantum increase in breeding ratio (BR) is achieved with metallic fuels. Ternary alloys of $\mathrm{U}-\mathrm{Pu}-\mathrm{Zr}$ containing $10 \mathrm{wt} . \%$ of $\mathrm{Zr}$ have been used as fuels in the fast reactors in the past. Addition of zirconium has two objectives: (i) to increase the solidus temperature of the fuel and (ii) to inhibit the inter diffusion of the clad components, Fe, Ni etc and the fuel constituents, U, Pu, fission products etc which could lead to the formation of low melting eutectic alloys. Studies carried out at IGCAR on U-Pu-Zr alloys with varying $\mathrm{Zr}$ contents (Riyas and Mohanakrishnan 2008) have shown that BR increases with reducing $\mathrm{Zr}$ content. Hence it is proposed to optimize the zirconium contents ( $6 \%$ or lower values) using test irradiations in FBTR so that higher breeding can be ensured. These ternary fuel alloy rods will be produced by injection casting and the pins will be fabricated with sodium bonding. U$15 \mathrm{Pu}$ fuel with $150 \mu \mathrm{m} \mathrm{Zr}$ liner on inner clad (to prevent fuel-clad interaction) is also being studied as advanced fuel for FBR in India. The BR of this fuel is calculated to be 1.45 with a fuel doubling time of $9 \mathrm{y}$. It is proposed to carry out test irradiation on pins with U-15 Pu binary alloys also. These mechanically bonded fuel pins will be fabricated by co-extrusion of the fuel, liner and the clad tube. The metal-fuel composition for the commercial fast reactors will be based on the results of the test fuel pins of ternary and binary alloy fuels, post-irradiation studies, modelling and development of the pyrometallurgical reprocessing needed for the metal fuels. Development of the fuel rod fabrication through injection casting, sodium bonding, co-extrusion for mechanically bonded fuel pins and development of pyrometallurgical reprocessing are being pursued.

\section{Achievements in research on structural materials for core of $\mathbf{F B R}$}

Fast neutrons, which have lower cross sections for fission, demand an increase in neutron flux $\left(\sim 10^{15} \mathrm{n} / \mathrm{cm}^{2} / \mathrm{s}\right)$ by an order of magnitude over the thermal reactors to achieve the desired linear heat rates. The core materials are, therefore, subjected to a demanding environment of high fast neutron flux coupled with high temperatures and high thermal gradients due to high heat transfer property of sodium to extract heat efficiently (sodium is the preferred choice from efficient heat removal point of view, both under steady and transient conditions). High flux of fast neutrons induces atomic displacements in the core structural materials leading to phase instabilities, void swelling, irradiation creep and changes in mechanical properties. These phenomena are interlinked and it has been shown that void swelling depends sensitively on the evolution of phases in austenitic stainless steels and has the dominant influence on irradiation creep behaviour, mechanical strength and ductility. Variations in chemical composition and microstructure influence void swelling and irradiation creep. Thus the solution to this mega challenge is judicious choice of composition and tailoring of microstructures.

Void swelling, irradiation creep and irradiation embrittlement arising out of fast neutron exposure of core structural materials are important phenomena that determine the residence time of fuel elements in the core of FBRs. For economic viability, the target burnup required for FBRs are more than 20 atom\% of heavy metal $(200,000 \mathrm{MWd} / \mathrm{t})$, and this can be achieved only by the availability of materials resistant to void swelling, irradiation creep and irradiation embrittlement, as well as satisfying the high temperature mechanical properties. Since fuel cycle cost is strongly linked with burnup, selection of materials resistant to void swelling and irradiation creep is an important research endeavour.

Structural materials for fast reactor core components have evolved continuously over the years resulting in substantial improvement in the fuel performance. The first generation materials belonged to austenitic stainless steel type SS 304 and 316 grades. These steels quickly reached their limits because of unacceptable swelling at doses higher than about 50 displacements per atom (dpa). The term dpa is conventionally used by FBR experts for quantifying the effects of irradiation on structural materials in terms of average number of displacements that each atom undergoes, which indirectly means the amount of vacancies/interstitials created under irradiation. One dpa is approximately equal to cumulative neutron dose of $3 \times 10^{21}$ neutrons $/ \mathrm{cm}^{2}$. Many improvements were made by changing percentage of major and minor elements and by modification of the microstructures by introducing cold work. This has led to the development of advanced core structural materials such as alloy D9 for which the incubation dose for swelling is improved compared to $316 \mathrm{SS}$.

For doses above $120 \mathrm{dpa}$, austenitic stainless steels are not employed, as void swelling is found to be substantial. Though ferritic/martensitic steels such as modified $9 \mathrm{Cr}-$ 1Mo and HT9 exhibit high void swelling resistance than 
conventionally used austenitic stainless steels, these alloys display poor thermal creep strengths at temperatures above $923 \mathrm{~K}$. This has led to restriction in achieving high burnup of fuel with clad operating at temperatures in the range 870-970 K. However, oxide dispersion strengthening (ODS) is a promising means of extending the creep resistance of ferritic/martensitic steels beyond $973 \mathrm{~K}$ without sacrificing the inherent advantages of high thermal conductivity and low swelling of ferritic-martensitic steels. In the following paragraphs details of selected research that has enabled development of the above high performance materials are highlighted.

\subsection{Austenitic stainless steels}

The main factor that currently limits fast reactor fuel life, and thus the burnup, is void swelling. The void swelling produces dimensional changes in the wrapper and thus makes the loading and unloading operations difficult. Therefore, the main challenge in fast reactor materials technology today is the development of low swelling materials for in-core applications (Baldev Raj et al 2008). The first generation materials were of SS 316 type, which exhibited high swelling beyond 50 dpa. A 20\% CW SS316 has been used in the clad and wrapper of FBTR. TEM analysis on the irradiated wrapper of FBTR shows the presence of voids beyond 40 dpa (figure 2) (Venkiteswaran et al 2007). Since the minor alloying elements like $\mathrm{Ti}, \mathrm{Si}, \mathrm{P}$ strongly influence the void swelling resistance of austenitic steels, a modified version of $316 \mathrm{SS}$ with $15 \mathrm{Cr}-$ $15 \mathrm{Ni}-2 \cdot 3 \mathrm{Mo}$ and Ti additions (alloy D9) has been developed for the $500 \mathrm{MWe}$ PFBR under construction in India.

In alloy $\mathrm{D}$ 9, the $\mathrm{TiC}$ forms as fine scale precipitates when appropriate thermomechanical treatments are used. Fine precipitates of $\mathrm{TiC}$ are strong neutral sinks for vacancies and interstitials and hence act as sites for increased recombination of vacancies and interstitials. This increase in recombination reduces the swelling in these

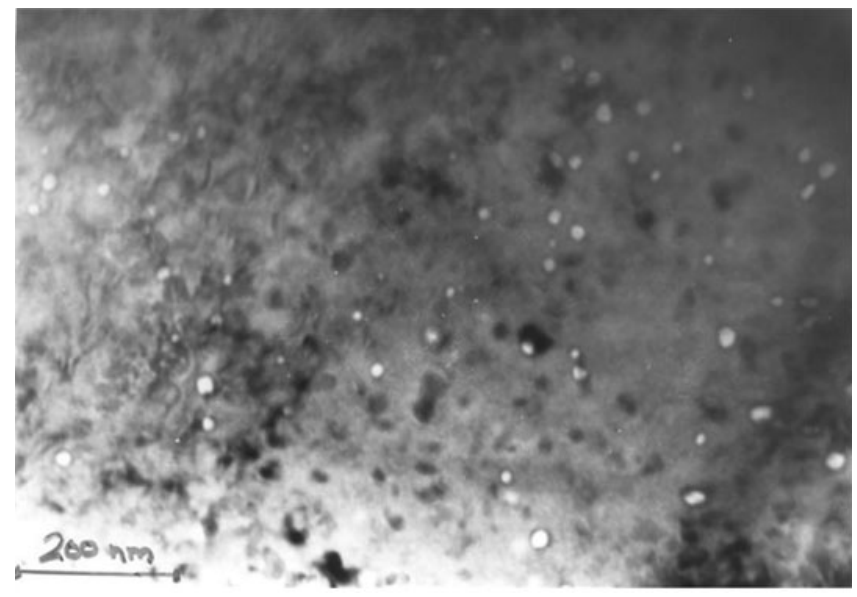

Figure 2. Voids in a wrapper of FBTR with 40 dpa. alloys. Figure 3 shows the high resolution lattice imaging of TiC in $20 \%$ cold worked D9, aged at $823 \mathrm{~K}$ for $100 \mathrm{~h}$. The inset shows a small region of the image after noise filtering, at the same magnification. These fringes provide information about the lattice strain around the precipitates. The lattice strain is responsible for the superior void swelling resistance of $\mathrm{D} 9$. The void swelling behaviour of alloy D9 with $0.25 \mathrm{Ti}$ and $0.15 \mathrm{Ti}$ are studied using heavy ion irradiation for understanding the influence of titanium in the void swelling resistance of the alloys (David et al 2008). The cold worked samples have been pre-implanted with a uniform helium concentration of 30 appm spanning a width of about $640 \mathrm{~nm}$. This was followed by a $5 \mathrm{MeV}$ nickel ion irradiation to create a peak damage of $\sim 100 \mathrm{dpa}$ at a damage rate of $7 \times 10^{-3} \mathrm{dpa} / \mathrm{s}$ at various irradiation temperatures between 700 and $970 \mathrm{~K}$. The gross swelling in the implanted range is measured by step height measurements and presented in figure 4 . It is found that the peak swelling temperatures and the magnitude of swelling for the alloys are different. The swelling at the peak swelling temperature of the alloys with $0.25 \%$ of $\mathrm{Ti}$ and $0 \cdot 15 \%$ of $\mathrm{Ti}$ are found to be $\sim 4 \%$ and $\sim 15 \%$, respectively. In order to understand the drastically different behaviours of the two alloys with regard to void swelling, the TiC precipitate formation in these two alloys was studied by positron lifetime measurements. The unirradiated alloys were subjected to isochronal annealing and the positron life time was measured after each annealing. These alloys show different TiC precipitate formation behaviour (figure 5). The observed variation of lifetime $\tau$ displays distinct stages viz. a monotonic decrease in $\tau$ from the initial cold worked state up to

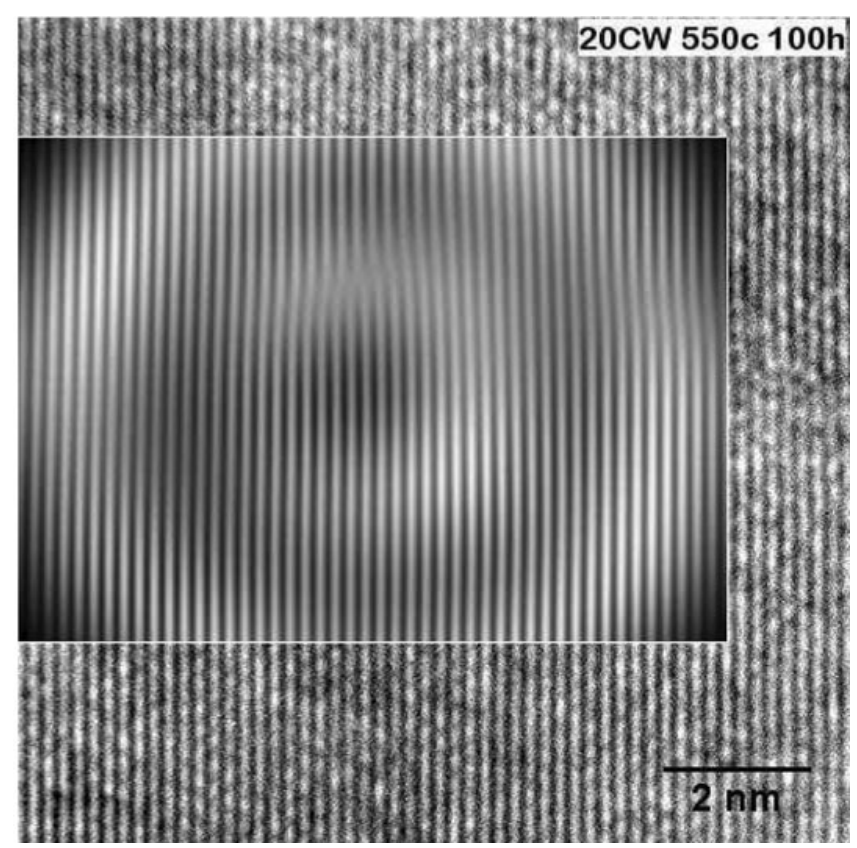

Figure 3. $\mathrm{TiC}$ in austenite matrix of alloy D9. 
$\sim 900 \mathrm{~K}$ in sample $\mathrm{B}$ and $\sim 800 \mathrm{~K}$ in sample $\mathrm{A}$. This is followed by a stage where there is an increase in lifetime to saturation, followed by a decrease in lifetime. The first stage corresponds to point defect recovery. This is

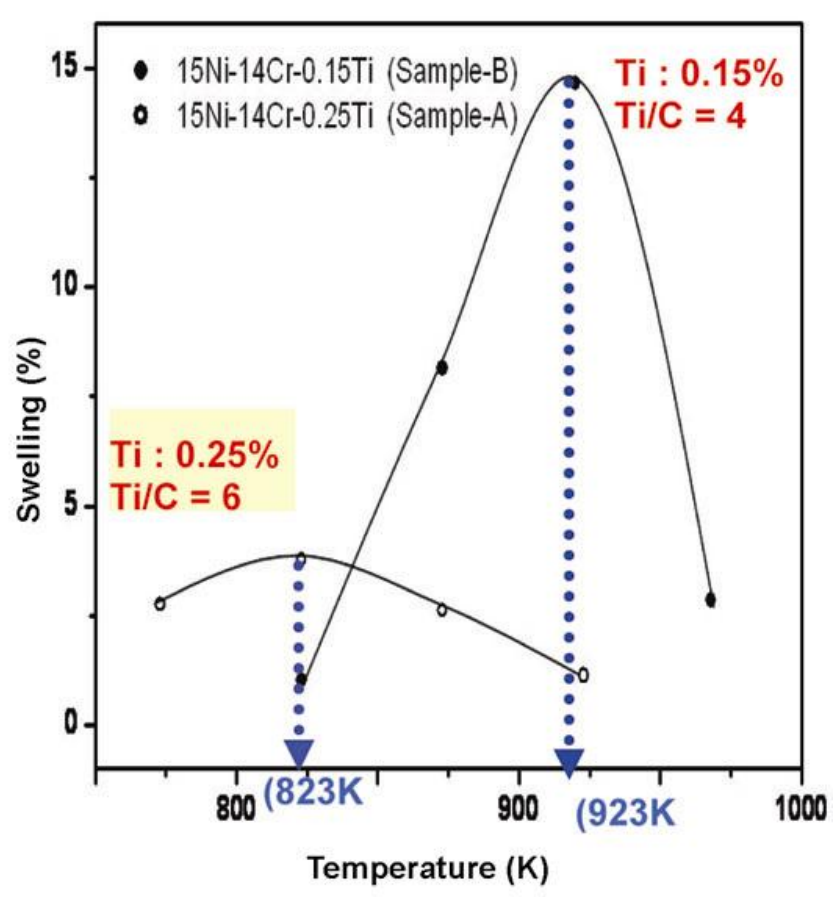

Figure 4. Temperature dependence of void swelling measured by surface profilometry for the D9 alloys.

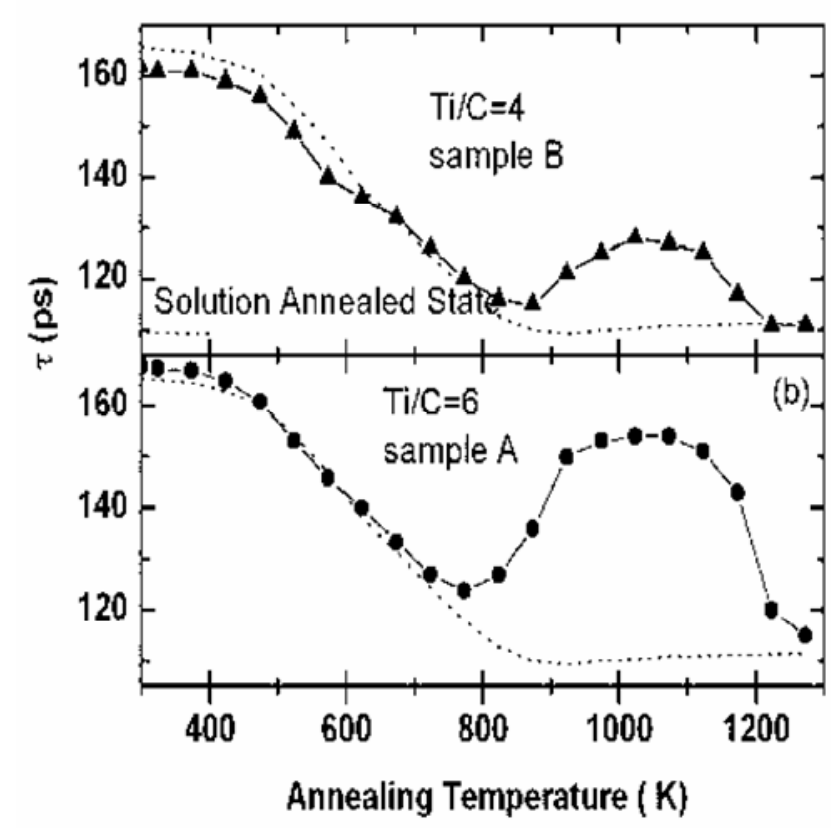

Figure 5. Variation of positron lifetime with annealing temperature for the cold-worked D9 alloys with different titanium concentrations explained by the migration of vacancies to sinks such as cold worked dislocations resulting in the annihilation of dislocations. The subsequent stage where there is an increase in lifetime $\tau$ is the result of positron trapping by the $\mathrm{TiC}$ precipitate which forms during heat treatment. The increase in average lifetime of positrons is due to the increase in the number density of $\mathrm{TiC}$ precipitates (beyond $750 \mathrm{~K}$ in sample $\mathrm{A}$ and beyond $850 \mathrm{~K}$ in sample $\mathrm{B}$ ), which are effective in reducing the swelling. The higher average lifetime of positrons in alloy D9 containing 0.25 Ti (sample A) compared to alloy D9 having $0.15 \mathrm{Ti}$ indicates higher volume fraction of $\mathrm{TiC}$ precipitates in sample A giving rise to low swelling in this alloy. Also, the shift in peak swelling temperature is also correlated with the onset of $\mathrm{TiC}$ precipitation.

\subsection{Ferritic/martensitic steels}

In the long term, ferritic-martensitic steels (9-12\% Cr) have been identified as the core component structural material, due to the inherent low swelling behaviour of $b c c$ ferrite. However, the increase in the ductile to brittle transition temperature (DBTT) due to irradiation is a cause of serious concern for use of ferritic steels. Several steps have been taken to obtain improved performance of the steel with respect to high temperature creep strength and embrittlement problem. This includes modification of the steel through alloying additions, control of tramp elements and tailoring of microstructure through metallurgical treatments. The upper shelf energy and shift in DBTT saturate at irradiation doses of about $20 \mathrm{dpa}$. Increase in toughness has been obtained by ensuring a fully martensitic structure, avoiding formation of delta ferrite in $12 \mathrm{Cr}$ steels by suitable chemistry. Refining the prior austenite grain size by optimizing the austenitizing temperature and tempering treatments are methods to reduce the strength and improve the toughness of the $9-12 \% \mathrm{Cr}$ steels. $9 \mathrm{Cr}-1 \mathrm{Mo}$ grades of ferritic steels are reported to show the lowest increase in DBTT among the ferritic grades (Kohyama et al 1996). Hence, the $9 \mathrm{Cr}-1 \mathrm{Mo}$ class of steel is being considered for wrapper in future FBRs. However, there are many challenging issues regarding joining for ferritic-martensitic steels and embrittlement in ferritic steels which are discussed below.

\subsection{Type IV cracking of ferritic steel weld joints}

The creep strength of the ferritic steel weld joint is lower than that of the weld metal because of type IV cracking, which is characterized by creep cavitation and fracture in fine grained/intercritical heat affected zone (FGHAZ/ ICHAZ) of the weld joints. Creep studies on simulated HAZ specimens have shown that creep strength of these zones are lower than that of the base metal, weld metal and coarse grained heat affected zone (CGHAZ). In the 
case of weld joint, deformation of weak FGHAZ/ICHAZ are constricted by relatively strong base metal on one side and CGHAZ on the other side during creep resulting in triaxial stress state which results in cavitation and final fracture in this zone with very little ductility. Figure 6 shows a schematic representation of type IV cracking in the creep test of ferritic steel weld joint (Albert et al 2005). Although it is difficult to avoid type IV cracking, several methods are being adopted to improve type IV cracking resistance. Strength homogeneity across the weld joint can be improved by normalizing the component after welding.

\subsection{Dissimilar weld joints}

Dissimilar metal welds (DMWs) between austenitic SS and $\mathrm{Cr}-\mathrm{Mo}$ ferritic steels are prone to extensive service failures due to large thermal stresses induced at the weld fusion line because of difference in coefficients of thermal expansion (CTE) between ferritic steel base metal and weld metal. A unique trimetallic transition joint between austenitic SS and Cr-Mo steel, with an intermediate Alloy 800 piece has been designed, developed and characterized (Bhaduri et al 2003). The trimetallic transition joint, 316LN SS/alloy $800 / \mathrm{mod}$. 9Cr-1Mo steel adopted for the steam generator circuit of the $500 \mathrm{MWe}$ PFBR has shown a factor of four improvements in life under thermal cycling conditions. The long-range diffusion of carbon during high temperature exposure of dissimilar ferritic joint results in the formation of hard and soft zones in the weldments. The driving force for diffusion of carbon is shown to be the chemical potential gradient across the joints. The formation of these zones leads to degradation of mechanical properties and shorter endurance of the welded component. Use of diffusion interlayers as barriers between the joints could prevent the formation of deleterious zone at the weld interface. The effectiveness of a nickel alloy Inconel 182 , as a diffusion barrier in a $9 \mathrm{Cr}-$ $1 \mathrm{Mo}$ and $2 \frac{1}{4} \mathrm{Cr}-1 \mathrm{Mo}$ joint has been demonstrated by a computational approach. Since interaction parameter of carbon and nickel is positive $\left(\varepsilon_{\mathrm{C}}^{\mathrm{Ni}}=+2 \cdot 0\right)$ in the Inconel interlayer, reduction in the driving force for diffusion of carbon (chemical potential gradient) and prevention of

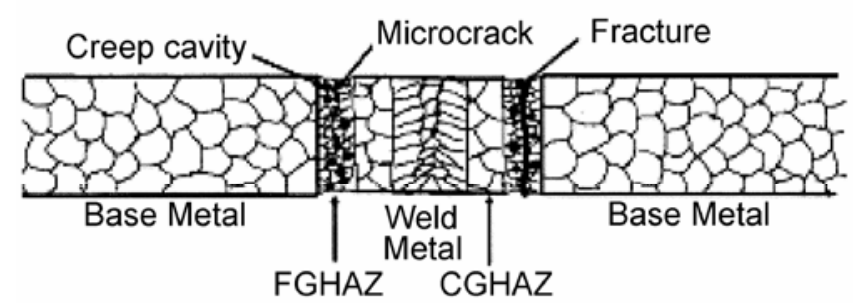

Weld Joint

Figure 6. Schematic representation of type IV cracking. hard and soft zones is expected. A theoretical model based on the finite difference technique was developed to simulate the high temperature carbon diffusion profile and evaluate the optimum thickness of the nickel interlayer required to prevent the formation of hard and soft zones. The optimum thickness of the Inconel interlayer between $9 \mathrm{Cr}-1 \mathrm{Mo}$ and $2 \frac{1}{4} \mathrm{Cr}-1 \mathrm{Mo}$ joints was found to be about 80 microns. Further the calculation was extended to other elements that have positive interaction with carbon in place of nickel-based interlayer. Calculation showed that, copper and cobalt could also act as effective diffusion barriers like nickel-based Inconel 182 interlayer (Anand et al 2006; Sudha et al 2006).

\subsection{Monte-Carlo and percolation model to identify the number of coincidence site lattice (CSL) boundaries to suppress embrittlement in ferritic steels}

A serious drawback of the ferritic alloys is embrittlement, which can possibly be overcome by tailoring the grain boundaries. The propensity for intergranular crack propagation in materials depends on the type and chemistry of grain boundaries. Low energy coincidence site lattice boundaries are highly resistant to crack propagation and are referred to 'special' boundaries, while the other high energy 'random' boundaries are preferential sites for segregation and precipitation of embrittling phases which lead to nucleation and propagation of cracks. Grain boundary engineering concerns with identification of individual grain boundaries and maximization of special boundaries or CSL boundaries. The intergranular crack network in a simulated three-dimensional Poisson-Voronoi (PV) polyhedral grain structure has been studied using percolation model. Using this model, the critical fraction of crackresistant 'special' boundaries required for a material to exhibit least susceptibility for crack percolation is found to be $\sim 0.8$ (Karthikeyan et al 2007). In the PV model, the grains were assumed to start growing from these nuclei at the same instant of time, at a uniform rate in an isotropic manner. Individually, each grain would then grow as spheres about each nuclei. The grain would grow until it impinges with the neighbouring grain to form a grain boundary plane. For a grain near a cube surface, the intersection of the grain with the cube wall forms the grain boundary. By this procedure, all the grain boundaries were identified.

The boundaries are randomly distributed into a fraction ' $f$ ' of 'special' boundaries, while the remaining $(1-f)$ are 'random' boundaries. The critical amount of crack resistant boundaries required to prevent the percolating one-dimensional chain network of 'random' boundaries have been evaluated as the 'percolation threshold'. A grain boundary is classified to be either a 'special' or a 'random' boundary by Monte Carlo method; a grain boundary is assigned to be 'special' with a probability ' $f$ ' 
or 'random' with a probability ' $1-f$ '. A crack is assumed to propagate only along the non-special or 'random' boundaries and terminate at a special boundary. The fictitious grain boundary formed between the grain and the cube wall is taken to be always 'special' in this analysis. In grain boundary character distribution (GBCD) analysis, the low angle/low CSL boundary are usually found to exhibit the 'special' boundary properties, while the other high CSL/high angle boundaries are taken as 'random' boundaries. A crack is assumed to propagate from one boundary to the other, only if the next grain boundary is a 'random' boundary. On the other hand, if all its neighbouring boundaries are 'special', then the crack would not propagate but terminate. The realization of the statistical event of crack propagation from one cube wall to the opposite, or in other words the statistical probability for occurrence of interconnected random boundary network joining one cube face to the opposite has been evaluated by Monte Carlo simulations. The resultant probability as a function of fraction ' $f$ ' of 'special' boundaries is given in figure 7 , based on $1000 \mathrm{MC}$ cycles. A transition from a high probability of percolation to a low probability, is seen to occur at (pc) $f \sim 0 \cdot 80$, as expected based on the percolation theory. Also, three runs were carried out corresponding to three different starting PV grain structures. The transition was found to always occur at $\sim 0 \cdot 80$, indicating the uniqueness of the threshold value for any PV lattice structure. The above model is at best a geometric model and not system specific. However, the model has provided the required insight into the procedures for engineering the grain boundaries, to achieve the desired reduction in DBTT.

\subsection{Oxide dispersion strengthened alloys}

The ferritic-martensitic alloys $(9-12 \% \mathrm{Cr})$ exhibit higher void swelling resistance than conventionally used austenitic stainless steels under irradiation. These steels are

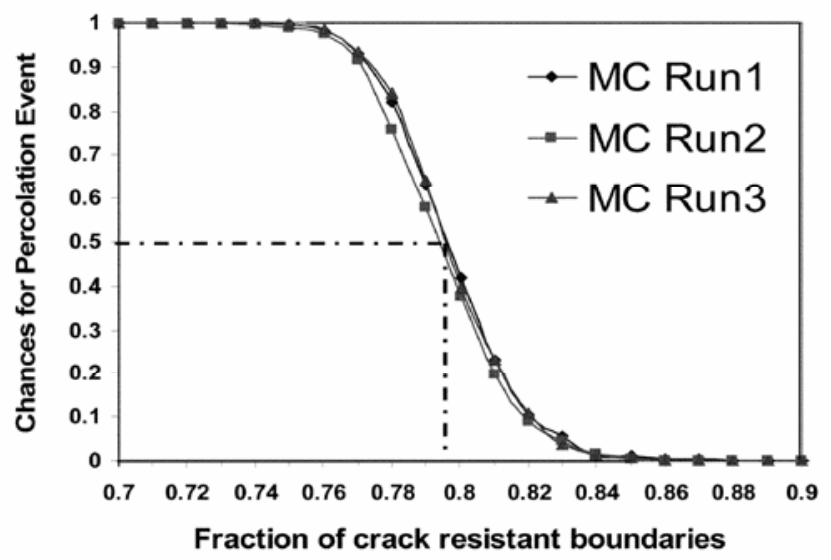

Figure 7. Probability of percolation event as a fraction of 'special' boundaries. suitable for a variety of coolant and tritium breeding options and have good mechanical strength only up to $773-823 \mathrm{~K}$. This disadvantage of low mechanical strength at high temperatures can be overcome by introducing thermally stable oxide dispersions in the ferrite or ferrite/ martensite matrix. Yttria $\left(\mathrm{Y}_{2} \mathrm{O}_{3}\right)$ is the main oxide additive used. The dispersed fine $\mathrm{Y}_{2} \mathrm{O}_{3}$ oxide particles improve high temperature strength by blocking mobile dislocations and retard irradiation swelling by acting as trapping sites for point defects induced by irradiation. These oxide dispersion strengthened steels may enable even higher service temperatures up to $923-1073 \mathrm{~K}$ in sodium cooled fast reactor applications and in the blanket systems of the fusion reactors if fabrication and joining issues can be satisfactorily resolved.

The formation of $\mathrm{Y}-\mathrm{Ti}-\mathrm{O}$ oxide nanocluster in $\mathrm{Fe}$ based alloys is obtained upon mechanical alloying, which is known to produce high concentration of vacancies. Even though $\mathrm{O}$ atom has very low solubility in defect free $\mathrm{Fe}$, a large solubility for the $\mathrm{O}$ atom is observed in $\mathrm{Fe}$ matrix processed by mechanical alloying. Further, even though the individual oxide phases of the constituents of nanoclusters $\left(\mathrm{Y}_{2} \mathrm{O}_{3}, \mathrm{TiO}_{2}\right)$ are stable, the $\mathrm{Y}-\mathrm{Ti}-\mathrm{O}$ complex oxide is found to be highly stable. Ab initio calculations based on density functional theory are carried out to understand the formation and stability of these nanoclusters, especially the role of vacancies, produced by mechanical alloying, and the role of $\mathrm{Y}$ and $\mathrm{Ti}$ in the stability and structure of these complex oxide nanoclusters. Our $a b$ initio density-functional theory (DFT) calculations of $\mathrm{Y}, \mathrm{Ti}, \mathrm{O}, \mathrm{Cr}$ and their clusters in bcc $\mathrm{Fe}$ show strong binding of $\mathrm{Y}, \mathrm{Ti}, \mathrm{O}$ clusters in the presence of vacancy leading to the enrichment of these elements at the core of the nanocluster. Further the interaction of $\mathrm{Cr}$ with $\mathrm{Y}$ and $\mathrm{Ti}$ is found to be repulsive, resulting in the depletion of $\mathrm{Cr}$ in the core of the nanocluster (Murali et al 2009). This strong binding has a bearing in the size distribution of nanoclusters. The binding energy of the defect clusters increases when we replace $\mathrm{Ti}$ with $\mathrm{Zr}$ (Baldev Raj et al 2008), which could have a positive effect on the fine dispersion of nanoclusters. This is in agreement with the experimental observation that the average particle sizes for the oxide nanoclusters decreases from $10-5 \mathrm{~nm}$ when $\mathrm{Ti}$ is replaced by $\mathrm{Zr}$ in ODS steel. Since fine size and uniform distribution of oxide particles are important from the point of high temperature creep and radiation stability of these oxide particles at high doses, further work is necessary to explore role of other minor alloying additions.

\subsection{Non-destructive evaluation}

Basic research in non-destructive evaluation has been carried out using ultrasonic, acoustic, electromagnetic and micro-magnetic NDE techniques in a variety of struc- 
tural materials after systematic heat treatments and microscopy as a primary step towards ensuring structural integrity of fast reactor components through enhanced understanding of the interaction of the interrogating medium with microstructures, stresses and defects for characterization of materials, assessment of material degradation and evaluation of mechanical properties (tension, creep, fatigue crack growth, hardness and fracture toughness) (Baldev Raj et al 2003). As the dimensions of microstructural features are different, the detection capability of various NDE techniques differs depending upon the characteristics of the stimuli and the sensing/measurement system. Typical order of dimension of microstructural features (Hoeller 1987) is shown in figure 8. For characterization and quantitative evaluation of a material attribute, correlation is established between measured NDE parameters and the attribute after detailed experimentation.

Ultrasonic parameters (such as attenuation and velocity) and micro-magnetic parameters (coercive force and Barkhausen emission signal amplitude) have been used for determination of grain size and size distribution of second phases that occur during thermal ageing. Creep and fatigue damage has been characterized using parameters from acoustic emission (AE), ultrasonic, acoustic harmonic, magnetic Barkhausen emission (MBE), acoustic Barkhausen emission, positron annihilation, X-ray diffraction and small angle neutron scattering (Baldev Raj et al 2003). Ultrasonic spectral parameters have been used for evaluation of grain size in a wide range of microstructures, i.e. ferrite, ferrite + martensite and martensite in stainless steel 316 and Mod. 9Cr-1Mo steel (Anishkumar et al 2003). Ultrasonic techniques have been developed for monitoring reduction in dislocation density and recrystallization in cold worked D9 alloy. Non-linear ultrasonic (NLU) technique that analyses the second harmonic amplitude based beta parameter has been found to

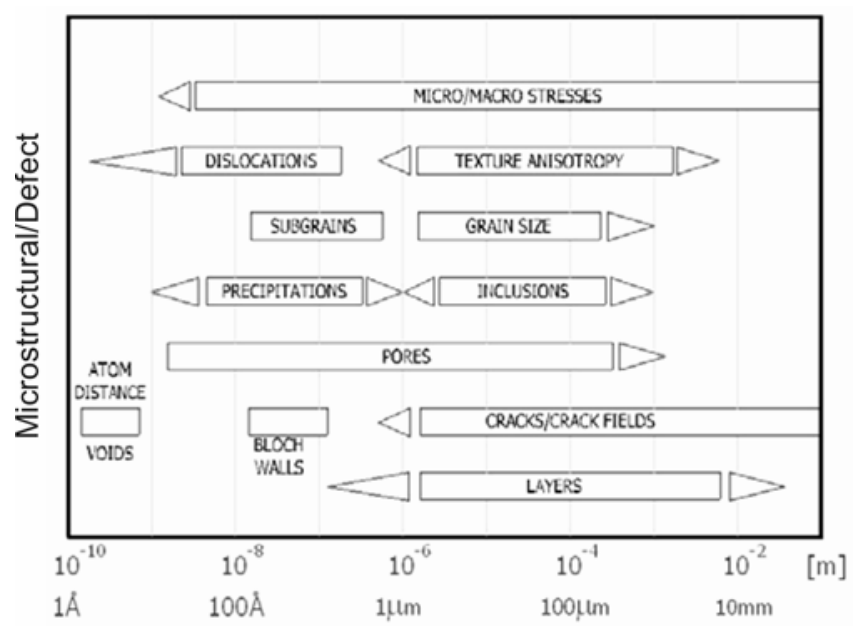

Figure 8. Dimension of various microstructural features. be very sensitive to changes in dislocation density, substructure changes and associated formation of martensite in cold worked stainless steel 304 as typically shown in figure 9 and these observations are well correlated with ultrasonic, MBE, eddy current, superconducting quantum interference device (SQUID) and XRD parameters (Rao et al 2001). In order to detect degradation in microstructure of stainless steel welds, SQUID sensor (Junction area $5 \times 5 \mu \mathrm{m}$, sensitivity $10 \mathrm{fT} / \sqrt{ } \mathrm{Hz}$ ) based methodology that detects decrease in magnetic permeability, in turn the sensor output, due to formation of non-magnetic sigma ferrite in stainless steel $316 \mathrm{LN}$ welds during low cycle fatigue (LCF) has been developed (Nagendran et al 2007). Preliminary investigations reveal that by using tiny field deployable giant magneto-resistive (GMR) sensors, it is also possible to detect these changes without the need for using SQUID cryostat.

In $9 \mathrm{Cr}-1 \mathrm{Mo}$ steel used for steam generators, progressive deformation and damage during low cycle fatigue has been characterized using MBE peak height. Dislocation substructure evolution in different stages of LCF viz. cyclic hardening, softening and saturation, has been characterized using MBE parameters. These studies demonstrated the potential of $\mathrm{MBE}$ technique in monitoring fatigue damage and prediction of the remaining service life. Acoustic emission technique has been extensively used to study the deformation mechanisms, and to determine LCF and high cycle fatigue damage and fatigue crack propagation rate, from which severity of flaws can be estimated. Different stages of crack growth were characterized by $\mathrm{AE}$ technique (Baldev Raj et al 2003). Changes in ultrasonic absorption, velocity and NLU-beta parameter have been correlated with changes in disloca-



Figure 9. Variation of non-linear ultrasonic harmonic based beta parameter with increasing cold work of stainless steel 304 . 
tion substructure, dislocation density, micro-crack formation etc. Acoustic microscopy and atomic force acoustic microscopy have been employed to study precipitates in polycrystalline materials.

As the NDE techniques for microstructral characterization are complementary, the use of multiple NDE techniques and NDE parameters helps in isolating the influence of one or a combination of specific microstructure features, enabling characterization of microstructures in a holistic manner. This has been successfully demonstrated in the case of Maraging steel grade M250 which is a candidate material for reprocessing plant components. Using ultrasonic, eddy current, MBE, NLU, positron annihilation and XRD techniques, the changes in microstructures with ageing after solution annealing have been analysed and a comprehensive understanding of microstructures has been obtained (Rajkumar et al 2006). Development and use of integrated sensors detecting complementary responses from a region in a material simultaneously subjected to different NDE stimuli would be beneficial and efforts are underway in this direction.

\section{Enriched elemental boron}

High density compacts of boron carbide containing boron enriched in ${ }^{10} \mathrm{~B}$ isotope will be used in the control rods of the Indian fast breeder reactors (Rajan Babu 1996). Boron carbide is commercially produced by the carbothermic reduction of either boric acid or its anhydride, $\mathrm{B}_{2} \mathrm{O}_{3}$ (Alizadeh 2004). In this process, a significant quantity of boron is lost during the reduction and subsequent process steps (Subramanian and Suri 2004). An alternate process which does not involve significant loss of boron would be more suitable for the production of enriched boron carbide from boric acid (enriched in ${ }^{10} \mathrm{~B}$ ). Hence, an alternate scheme was developed to minimize the loss of enriched boron $(<10 \%)$. This process enables the recovery of boron from the process wastes as well. The steps involved in this process are: (i) enrichment of boron, (ii) conversion of boric acid into potassium fluoroborate, (iii) production of boron from potassium fluoroborate through fused salt electrolysis, (iv) purification of the cathode deposit by 'acid-leaching', (v) production of boron carbide by direct reaction of the elements and (vi) consolidation of the boron carbide powder. Enrichment of boron (in ${ }^{10} \mathrm{~B}$ isotope) is being carried out in India by both ion exchange process and $\mathrm{BF}_{3}$-diethylether distillation processes. After enrichment, elemental boron was produced through electro-winning from potassium fluoroborate dissolved in a mixture of molten potassium fluoride and potassium chloride. In order to generate the fundamental data required for building a facility for the production of elemental boron (steps (ii) to (iv)) based on the above scheme, a 'demonstration facility' is currently being operated at IGCAR. Elemental boron is recovered from a near-saturated solution of $\mathrm{KBF}_{4}$ in a molten mixture of $\mathrm{KCl}$ and $\mathrm{KF}$ held at $1073 \mathrm{~K}$ in a graphite crucible, by the application of a d.c. potential (1.5-4.5 V). During this electrolysis boron is electrodeposited on a mild steel cathode, while chlorine evolves at the graphite crucible, which serves as the anode. The elemental boron obtained using the above process is purified further, in order to remove the major impurities viz. $\mathrm{Cl}^{-}, \mathrm{F}^{-}, \mathrm{Fe}$ and $\mathrm{Ni}$. Many trial runs were carried out in order to optimize the process parameters. Through extensive research on the electrolytic process, it was established that elemental boron powder with a purity of $95-99 \%$ could be produced using high temperature molten salt electro-winning process. The major impurities were found to be oxygen, carbon, iron and nickel.

\section{Chemistry of liquid sodium coolant and development of chemical sensors}

Liquid sodium coolant is quite compatible with structural steels. Although corrosion and mass transfer is anticipated in sodium circuits because of the use of different structural steels and/or existence of temperature gradients, this rate is very low in pure sodium owing to the low solubility of the alloying elements of steels in sodium (Mathews and Borgstedt 1987). In presence of dissolved non-metallic impurities such as oxygen and carbon, this rate gets marginally enhanced which needs to be considered in view of the long service life of the components in the reactor. Since the corrosion in oxygen contaminated sodium involves formation of various ternary compounds such as $\mathrm{NaM}_{x} \mathrm{O}_{y}(\mathrm{M}=$ alloying constituents of the structural steels), a knowledge of the phase diagrams of the $\mathrm{Na}-\mathrm{M}-\mathrm{O}$ systems and the thermochemical data of the relevant ternary compounds are essential. Phase diagrams of $\mathrm{Na}-\mathrm{Fe}-\mathrm{O}$, Na-Mo-O, $\mathrm{Na}-\mathrm{Cr}-\mathrm{O}$ and $\mathrm{Na}-\mathrm{Ni}-\mathrm{O}$ systems were established and thermochemical data of ternary compounds of these systems had also been measured at IGCAR (Sreedharan et al 1983; Gnanasekaran et al 1989; Sridharan et al 1993). From these data, the threshold oxygen concentrations for the formation of these ternary compounds in sodium systems could be obtained which corroborated with the experimental observation of $\mathrm{Na}$ $\mathrm{CrO}_{2}$ being the stable compound in sodium-steel systems when oxygen concentration in sodium is low. Study of the phase stability in $\mathrm{Na}-\mathrm{Cr}-\mathrm{O}-\mathrm{C}$ system showed the need for higher threshold oxygen levels for $\mathrm{NaCrO}_{2}$ formation in sodium with increase in carbon activity in sodium. These results also rationalized the different threshold oxygen levels observed for formation of $\mathrm{NaCrO}_{2}$ in large sodium systems wherein both dissolved oxygen and carbon would be present (Gnanasekaran and Mathews 1986).

Solid electrolyte based oxygen sensors are required for continuous monitoring of oxygen in sodium. Since the prevailing oxygen potentials in sodium are very low, oxide 
ion conducting solid electrolytes with suitable lower electrolytic boundaries need to be chosen. Calcia stabilized zirconia (CSZ) solid electrolyte coated with $\mathrm{CaZrO}_{3}$ was investigated for its use for this application (Periasami et al 1988). Although, sensors based on this electrolyte could be used in sodium, their success depended on the $\mathrm{CaZrO}_{3}$ coating characteristics. Yttria doped thoria (YDT) electrolyte meets the criterion of the suitable electrolyte but sintering of components made from YDT powders prepared by conventional techniques requires temperatures as high as $2000^{\circ} \mathrm{C}$. Through a novel combustion technique, nano sized YDT powders were prepared whose compacts could be sintered to yield products with $\sim 99 \%$ T.D. at $1600^{\circ} \mathrm{C}$ (Jayaraman et al 2007). Miniature sensors wherein YDT in the form of short thimbles glass soldered to an iron-nickel alloy of matching coefficient thermal expansion are being tested in liquid sodium.

At the steam generator of the fast breeder reactor, high pressure steam is separated from liquid sodium by ferritic steel tube with a wall thickness of $\sim 4 \mathrm{~mm}$ which are subjected to strict quality control during the fabrication of the component. However, if a defect develops during the operation of the steam generator, high pressure steam would enter into sodium and lead to wastage of the leaky and the nearby healthy ferritic steel tubes (Hori 1980). Hence, any steam leak at its inception itself needs to be detected. Since a steam leak would lead to production of hydrogen, continuous monitoring of dissolved hydrogen levels in liquid sodium coolant is invariably used to detect the steam leak. Although hydrogen sensors based on measuring hydrogen diffusing from sodium through thin walled nickel thimbles using quadrupole mass spectrometer or current of the ion pumps in the system are being used in FBRs, they suffer from complex instrumentation and high cost. To meet this requirement of on-line monitoring of hydrogen, a simple and inexpensive electrochemical hydrogen sensor based on a hydride ion conducting

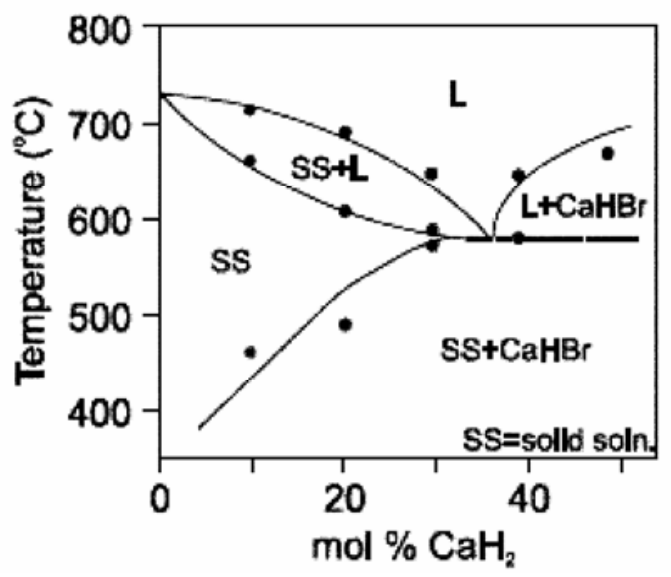

Figure 10. Phase diagram of $\mathrm{CaBr}_{2}-\mathrm{CaHBr}$. solid electrolyte has been developed at IGCAR. To select a solid electrolyte that possesses adequate conductivity, is thermodynamically stable under operating conditions in reactor and has a transport number of the $\mathrm{H}$-ions close to unity, study of phase diagrams of several alkali-alkaline earth halide-alkaline earth hydride systems and measuring electrical conductivity of candidate electrolytes were carried out (Joseph et al 2005). Based on the results of these studies, $\mathrm{CaHBr}-\mathrm{CaBr}_{2}$ based system, whose phase diagram is shown in figure 10, was chosen as the solid electrolyte. The schematic of an electrochemical sensor is shown in figure 11. Operation of this sensor in laboratory sodium loops and large sodium rigs has shown it to possess a detection limit of $50 \mathrm{ppb}$ of dissolved hydrogen in sodium (figure 12). If a steam leak occurs during low power operations of the reactor when the sodium temperatures in coolant circuits would be lower than the normal temperature of $\sim 550^{\circ} \mathrm{C}$, the hydrogen generated by the sodium-water reaction would not dissolve into sodium due to poor kinetics and would escape to argon cover gas. For continuous monitoring of hydrogen level in argon cover gas, a nickel diffuser based sensor using a thermal conductivity detector has been developed (Mahendran et al 1998). This sensor could be used for reliably measuring hydrogen levels as low as $30 \mathrm{ppm}$. For measuring hydrogen levels below $30 \mathrm{ppm}$ in argon, a very compact system using a semiconducting oxide based chemoresistive sensor has been developed and put to operation in sodium rigs (Prabhu et al 2005). Pd-doped tin oxide in the form of a thin film is used in this sensor and can sense from 2 to $80 \mathrm{ppm}$ of hydrogen in argon gas.

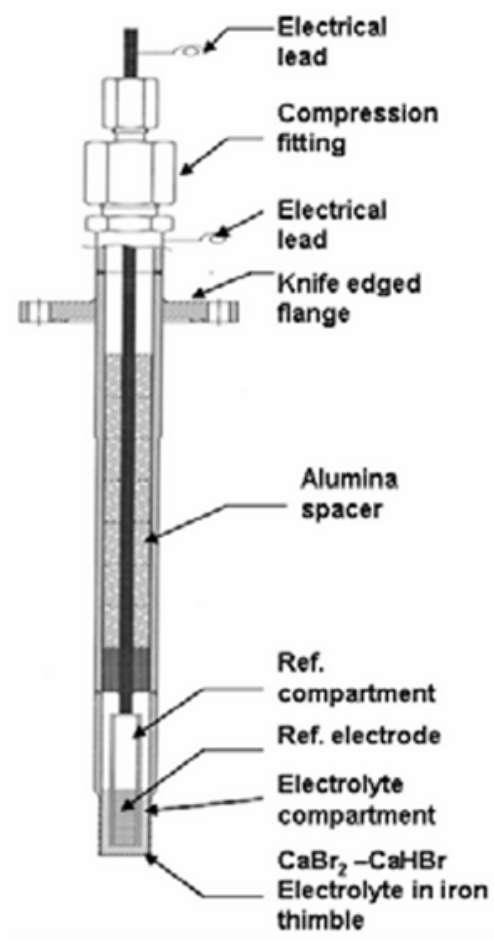

Figure 11. Schematic of electrochemical hydrogen sensor. 
Carbon is an important interstitial alloying element in steels. When carbon concentration in steels is changed beyond the specified limits, the mechanical properties are deleteriously influenced. Liquid sodium can become a source of carbon, in the event of a leak of hydrocarbon oil used as cooling fluids of the shafts of the centrifugal pumps into hot sodium leading to their cracking. It is, therefore, necessary to continuously monitor the activity of carbon in sodium. An electrochemical carbon sensor using molten carbonate electrolyte has been developed at IGCAR.

\section{Nuclear waste immobilization}

Safe disposal of the radioactive wastes is one of the challenging tasks undertaken by the nuclear industry. Borosilicate glass is the waste matrix of choice for the first generation waste all over the world. Newer and better matrices including glass and crystalline ceramics, such as iron phosphate glass (Day et al 1998; Perez Jr et al 2001) and synthetic rock or synroc (Lutze and Ewing 1988; Govindan Kutty et al 2006), are also being developed as waste forms for the future. Crystalline matrices can also be specially tailored as hosts for specific radioactive elements. For instance, it has been shown that the ceramic oxide material, $\mathrm{Gd}_{2} \mathrm{Zr}_{2} \mathrm{O}_{7}$, is an excellent host for plutonium (Wang et al 1999). Pu enters the oxide crystal structure (pyrochlore) as a dilute solid solution, and the structural speciality (interchangeability of the $\mathrm{Gd}$ and $\mathrm{Zr}$ ions on the cation sublattice) protects it against the damage induced by the $\alpha$-radiation from $\mathrm{Pu}$. Accelerated radiation damage studies by ion beam irradiation (Wang et al 1999) have shown that the material cannot be amorphized up to an irradiation level of $15 \mathrm{dpa}$, equivalent to 30 million years of storage of a $\mathrm{Gd}_{2} \mathrm{Zr}_{2} \mathrm{O}_{7}$ waste form containing $10 \mathrm{wt} \% \mathrm{Pu}^{239}$.

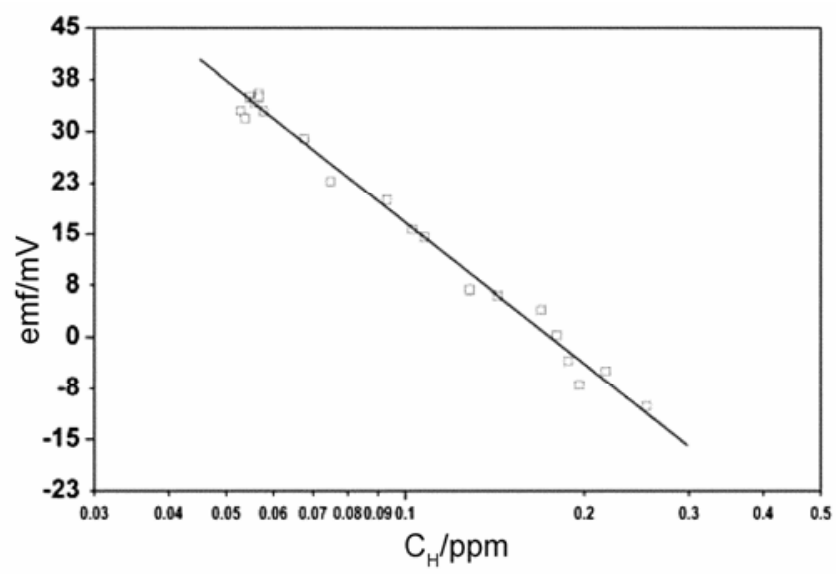

Figure 12. Variation in sensor output with dissolved hydrogen concentration in sodium.
Studies at IGCAR on the iron phosphate glass (IPG) system have shown that a waste form based on this can be readily prepared using the simulated high-level waste expected from FBTR (150 GWd/t burnup). The melting and pouring was carried out at $1323 \mathrm{~K}$, and there was no detectable waste loss in the process. The glass transition temperature of the waste-loaded glass was found to be the same as that of the pristine glass. The process parameters are being optimized. IPG was also found to be an excellent host for Cs. Up to $36 \mathrm{~mol} \% \mathrm{Cs}$ (inactive) could be easily loaded by melting at $1123 \mathrm{~K}$ (pouring temperature, $1263 \mathrm{~K}$ ) with negligible weight loss (Joseph et al 2009). Radioactive Cs-loaded IPG pencils can be developed for clinical applications.

\section{Conclusions}

Fast breeder reactor with closed fuel cycle is an inevitable technology option to provide energy security for India. India has matured in several advanced fields of fast breeder and associated nuclear fuel cycle technologies. Materials development and materials technologies, particularly the widely used austenitic stainless steels, discussed in this paper have a deterministic influence on the advancement and success of fast breeder programme. Stainless steels are exposed to challenging environments of radiation, temperature, stress and chemicals. Rigorous R\&D for alloy development complemented with detailed structure-property evaluation of relevant mechanical and corrosion behaviour data have been possible with the state of art facilities established at IGCAR. These data provide useful inputs for design engineers to ensure reliable and safe operation of the components. Advanced concepts in alloy design and grain boundary engineering have been utilized to enhance the corrosion resistance and mechanical properties of alloys. Enhancing the life of reprocessing plants to 60 years will significantly improve the economy of the closed fuel cycle, which imposes the need to develop corrosion resistant materials and coating technologies. The need for high breeding ratio necessitates evaluation of metallic fuel and reassessment of core component materials and back-end technologies. Advanced NDE techniques for assessment of manufactured components and in-service inspection have been developed, enhancing the confidence in the performance of the plant components and systems. The ultimate objective would be to shift from the present domain of materials limited life of components to design-basis life time performance of components without materials failure. These objectives complemented with enhanced design inputs, viz. 60-100 years design life of reactor, 2,00,000 MWd/t burnup of fuel, etc would result in improved economics, safety and reliability of the plant performance. Meeting these objectives is the key to realization of the vision to provide fast reactor electricity at an affordable and competitive price. 


\section{Acknowledgements}

The author acknowledges the contribution of Dr B K Panigrahi, Dr B P C Rao, Dr T Gnanasekharan, Dr K Nagarajan, Dr K V G Kutty, Dr S Anthonysamy and many other colleagues of IGCAR, Kalpakkam, whose scientific works are cited in this manuscript.

\section{References}

Albert S K, Tabuchi M, Hongo H, Watanabe T, Kubo K and Matsui M 2005 Sci. \& Technol. Weld. \& Join. 10149

Alizadeh A, Taheri-Nassaj E and Ehsani N 2004 J. Eur. Ceram. Soc. 243227

Anand R, Sudha C, Karthikeyan T, Saroja S, Terrance A L E and Vijayalakshmi M 2006 Proc. of the first south-east Asia international institute of welding congress (Bangkok, Thailand: Welding Institute of Thailand)

AnishKumar, Jayakumar T, Baldev Raj and Ray K K 2003 Mater. Sci. \& Engg. A362 58

Antony M P, Daniel J and Mathews C K 1997 Nucl. Technol. 117299

Anthonysamy S, Vasudeva Rao P R and Mathews C K 1989 Proceedings of international symposium on thermochemistry and chemical processing (Kalpakkam: IGCAR) p. 319

Baldev Raj, Moorthy V, Jayakumar T and Bhanu Sankara Rao K 2003 Int. Mater. Rev. 48273

Baldev Raj, Vijayalakshmi M, Sivaprasad P V, Panigrahi B K and Amarendra G 2008 Proceedings of the 29th Riso international symposium on energy materials - Advances in characterization, modelling and application (eds) N H Andersen et al (Risø: DTU)

Bhaduri A K et al 2003 Proc. seminar, Materials R\&D for PFBR (eds) S L Mannan and M D Mathew (Kalpakkam: Indian Institute of Metals) pp. 263-277

David C et al 2008 J. Nucl. Mater. 383132

Day D E, Wu Z, Ray C S and Hrma P 1998 J. Non-Cryst. Solids 2411

Ganguly C and Sengupta A K 1988 J. Nucl. Mater. 158159

Gnanasekaran T and Mathews C K 1986 J. Nucl. Mater. 140 202

Gnanasekaran T, Mahendran K H, Kutty K V G and Mathews C K 1989 J. Nucl. Mater. 165210

Govindan Kutty K V et al 2006 in Nuclear fuel cycle technologies-Closing the fuel cycle (eds) Baldev Raj and P R Vasudeva Rao (Mumbai: BRNS) pp. 341-350

Hoeller P 1987 in Non-destructive characterization of materials II (eds) J F Bussiere et al (Berlin: Springer-Verlag) p. 101

Hori M 1980 Atomic Energy Review 18707

Jayaraman V, Krishnamurthy D, Ganesan R, Thiruvengadasami A, Sudha A, Prasad M V R and Gnanasekaran T 2007 Ionics 13299

Joseph K, Govindan Kutty K V, Chandramohan $\mathrm{P}$ and Vasudeva Rao P R 2009 J. Nucl. Mater. 384262
Joseph K, Sujatha K, Nagaraj S, Mahendran K H, Sridharan R, Periaswami G and Gnanasekaran T 2005 J. Nucl. Mater. 344 285

Kandan R, Babu R and Nagarajan K 2004 J. Nucl. Mater. 324 215

Karthikeyan T, Saroja S, Vijayalakshmi M and Murthy K P N 2007 Frontiers in the design of materials (Hyderabad: Universities Press (India) Private Limited) pp. 109-120

Kohyama A et al 1996 J. Nucl. Mater. 233-237 138

Lutze W and Ewing R C 1988 Radioactive waste forms for the future (Amsterdam: North-Holland)

Mahendran K H, Sridharan R, Gnanasekaran T and Periaswami G 1998 Ind. Eng. Chem. Res. 371398

Mathews C K and Borgstedt H U 1987 Applied chemistry alkali metals (New York: Plenum Press)

Murali D, Panigrahi B K, Valsakumar M C, Sundar C S and Baldev Raj 2009 Appl. Phys. Letts (submitted)

Nagendran R et al 2007 IEEE Trans. Appl. Supercond. 173824

Perez Jr J M et al 2001 Pacific Northwest National Laboratory Report, PNNL-13582

Periaswami G 1988 Electrochemical studies related to the development of on-line meters for use in liquid sodium, $\mathrm{Ph} \mathrm{D}$ Thesis, University of Madras, Chennai

Prabhu E, Jayaraman V, Gnanasekar K I, Gnanasekaran T and Periaswami G 2005 Asian J. Phys. 1433

Rajan Babu V, Govindarajan S and Chetal S C 1996 Proc. of seminar on inherent engineered safety aspects of PFBR design (Kalpakkam: IGCAR)

Rajkumar K V et al 2006 Comprehensive characterization of ageing behaviour in M250 maraging steel using multiNDE techniques. Proc. 9th European conf. on NDT, Berlin (www.ndt.net/article/ecndt2006/doc/Fr.1.7.1.pdf)

Rao B P C, Jayakumar T, Baldev Raj and Arnold W $2001 \mathrm{~J}$. Non-destructive Eval. 2138

Riyas A and Mohanakrishnan P 2008 Ann. Nucl. Energy 3587

Sai Baba M, Vana Varamban S and Mathews C K 1987 J. Nucl. Mater. 14456

Sengupta A K, Goswami G L, Garg S P, Sayi Y S, Radhakrishna J and Sood D D 1986 in Proceedings of the seminar on fast reactor fuel cycle (Kalpakkam: IGCAR) Vol. 1, p. 50

Sengupta A K, Banerjee J, Jarvis T, Kutty T R G, Ravi K and Majumdar S 2003 Nucl. Technol. 142260

Sreedharan O M, Madan B S and Gnanamoorthy J B $1983 \mathrm{~J}$. Nucl. Mater. 119296

Sridharan R, Gnanasekaran T and Mathews C K 1993 J. Alloys \& Compd. 1919

Subramanian C and Suri A K 2004 Metals, Mater. \& Process. 1639

Sudha C, Thomas Paul V, Terrance A L E, Saroja S and Vijayalakshmi M 2006 Weld. Res. Suppl. 8571

Venkiteswaran C N et al 2007 International symposium on advances in stainless steels (eds) Baldev Raj et al (New Delhi: Allied Publishers Ltd)

Wang S X, Begg B D, Wang L M, Ewing R C, Weber W J and Govindan Kutty K V 1999 J. Mater. Res. 144470 